NASA Technical Memorandum 106605

\title{
Effects of Combined Stressing on the Electrical Properties of Film and Ceramic Capacitors
}

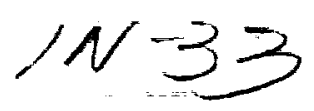

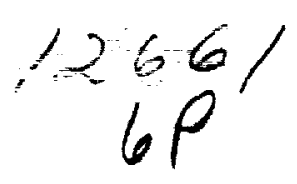 \\ 1266}

Eric Overton

National Aeronautics and Space Administration

Lewis Research Center

Cleveland, Ohio

Ahmad N. Hammoud

NYMA, Inc.

Engineering Services Division

Brook Park, Ohio

Eric D. Baumann and Ira T. Myers

National Aeronautics and Space Administration

Lewis Research Center

Cleveland, Ohio

$\begin{array}{lll}a & & \\ + & & \\ N & n & 0 \\ n & 0 & 0 \\ 1 & \frac{1}{4} & N \\ 0 & 0 & -1 \\ z & 5 & 0\end{array}$

Prepared for the

International Symposium on Electrical Insulation

sponsored by the Institute of Electrical and Electronics Engineers

Dielectrics and Electrical Insulation Society

Pittsburgh, Pennsylvania, June 5-8, 1994

National Aeronautics and Space Administration

Lewis Research Center

Cleveland, Ohio 44135

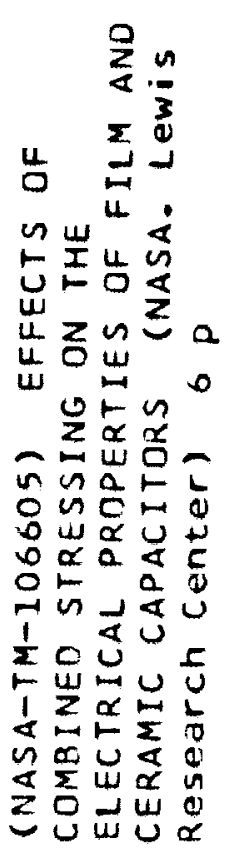




\title{
EFFECTS OF COMBINED STRESSING ON THE ELECTRICAL PROPERTIES OF FILM AND CERAMIC CAPACITORS
}

\author{
Eric Overton \\ National Aeronautics and Space Administration \\ Lewis Research Center \\ Cleveland, Ohio 44135 \\ Ahmad N. Hammoud \\ NYMA, Inc. \\ Engineering Services Division \\ Brook Park, Ohio 44142 \\ Eric D. Baumann and Ira T. Myers \\ National Aeronautics and Space Administration \\ Lewis Research Center \\ Cleveland, Ohio 44135
}

\begin{abstract}
Advanced power systems which generate, control and distribute electrical power to many large loads are a requirement for future space exploration missions. The development of high temperature insulating materials and power components constitute a key element in systems which are lightweight, efficient, and are capable of surviving the hostile space environment. In previous work, experiments were carried out to evaluate film and ceramic capacitors for potential use in high temperature applications. The effects of thermal stressing, in air.and without electrical bias, on the electrical properties of the capacitors as a function of thermal aging up to 12 weeks were determined. In this work, the combined effects of thermal aging and electrical stresses on the properties of teflon film and ceramic power capacitors were examined. The ceramic capacitors were thermally aged for 35 weeks and the teflon capacitors for 15 weeks at $200 \mathrm{C}$ under full electrical bias and were characterized, on a weekly basis, in terms of their capacitance stability and electrical loss in the frequency range of $50 \mathrm{~Hz}$ to $100 \mathrm{kHz}$. DC leakage current measurements were also obtained. The results obtained represent the influence that short-term thermal aging and electrical bias, have on the electrical properties of the power capacitors characterized.
\end{abstract}

\section{INTRODUCTION}

More often power systems are being designed with increased packaging and energy densities. Consequently, the components used in these power systems are faced with the challenge of operating reliably in harsh environments where stresses of different kinds, such as high temperatures, are encountered. Space exploration missions, nuclear-powered space vehicles, integrated engine electronics, and satellite power conditioning are examples of aerospace applications where high temperatures may be present [1]. Terrestrial applications where elevated temperatures are present include well-logging, geothermal energy extraction, nuclear power plants, and automotive and locomotive engine electronics. In addition to being an external factor, heat is generated by the power processing devices during normal operation. This internally-developed thermal stress eventually leads to catastrophic failure through gradual device degradation. The increased emphasis on higher energy densities and raising the power level of spaced-based power systems and components is causing more severe heat buildup problems. This direction is resulting in raising the operating temperature of the power devices [2]. With the developing demands of advanced space power electronic systems with emphasis on component size and weight reduction, and improved performance and reliability, naturally the development of high temperature power components becomes necessary.

The selection process began with identifying candidate capacitors which were lightweight and constructed of low loss, corona-resistant dielectric materials which are stable in harsh environments. Several $1 \mu \mathrm{F}$ teflon film and ceramic capacitors were selected and evaluated to determine their reliability in high temperature applications. The capacitors were thermally aged at a temperature of $200 \mathrm{C}$ with an applied electrical bias and characterized in terms of their capacitance stability and electrical losses at various frequencies. DC leakage current measurements were obtained as well. The effects of these combined stresses on the electrical properties of the capacitors were investigated and in this paper the experimental results will be discussed. 


\section{ExPermental Procedures}

In previous studies high temperature power capacitors made of metallized-teflon film (Component Research Company) and COG/NPO ceramic (Olean Advanced Products) were evaluated at high temperatures [3]. These experiments were carried out to analyze the effects of temperature on the stability of the various electrical properties of these capacitors. They were characterized at temperatures ranging from room temperature to $200 \mathrm{C}$. Experiments followed which studied the effects of short-term thermal aging on the electrical properties of the capacitors. These capacitors were thermally aged, in air, for a period of 12 weeks and characterized on a weekly basis. In the present work, the effects of simultaneous thermal aging and electrical stressing on the electrical properties of teflon and ceramic power capacitors were examined. Table I lists some of the design requirements and manufacturers specifications [4-5].

Three power capacitors from each type were selected for this thermal aging test. The number of candidates selected was restricted by availability and cost and based upon previous experimentation, this sample size is quite sufficient for these types of thermal aging tests.

The capacitors were prepared by soldering connectors onto the leads using a $\operatorname{Sn} 95 \mathrm{Ag} 5$ type solder rated for use at temperatures up to $220 \mathrm{C}$. After the necessary preparations and connections were completed the capacitors were then heated to a temperature of $200 \mathrm{C}$ with an electrical bias of 200 and 500 VDC applied to the teflon and ceramic capacitors, respectively. A Hotpack oven was used for the thermal aging process and the electrical bias was supplied by Keithley Model 237 Source Measurement Units and a Hewlett Packard 6030A Autoranging System Power Supply. The current to the capacitors was limited by $10 \mathrm{k} \Omega$ currentlimiting resistors.

This thermal aging test with applied bias was performed over a 35 week period for the ceramic capacitors and 15 weeks for the teflon capacitors and the electrical parameters measured were capacitance, electrical loss, and DC leakage current. The measurements were performed on a weekly basis and made after the components were allowed to cool gradually to room temperature from $200 \mathrm{C}$. This precautionary measure was taken to avoid the possible occurrence of thermal shock which could mechanically damage the capacitors.

After the components reached room temperature and were discharged, capacitance and dissipation factor measurements were taken over the frequency range of $50 \mathrm{~Hz}-100 \mathrm{kHz}$ using a GenRad 1689 Precision RLC Digibridge. This computer programmable Digibridge allows the system to operate in an automated mode. A Keithley 740 System Scanning Thermometer, also programmable, was used to monitor the oven temperature.

The DC leakage current measurements were made using the Keithley source measurement units which also supplied the electrical bias to the capacitors. The leakage currents were recorded after an electrification time of 5 minutes according to the ASTM standards. This time was required to allow the current to stabilize. The components under test were completely discharged prior to making each measurement by shorting the leads through a $10 \mathrm{k} \Omega$ resistor.

\section{RESULTS}

The three ceramic capacitors displayed similar behavior upon aging and showed good reproducibility. However, the teflon capacitors began to be very erratic after a few weeks and failed to show reproducibility either within the readings of a single capacitor from one week to the next, or from one capacitor to another, especially at the higher frequencies. However, individual measurements on a given day were in general quite reproducible.

The changes in capacitance of the teflon and the ceramic capacitors as a function of aging time at $50 \mathrm{~Hz}$ and $20 \mathrm{kHz}$ are shown in Figures 1 and 2, respectively. Although the data depicted in Figures 1 and 2 are representative for the frequencies of $50 \mathrm{~Hz}$ and $20 \mathrm{kHz}$, respectively; the ceramic capacitors displayed no dependency in their capacitance over the frequency range of $50 \mathrm{~Hz}-100 \mathrm{kHz}$. It can be clearly seen that the capacitance of the ceramic capacitors was very stable throughout the aging period. The COG type ceramic capacitors are known to have good temperature stability. The capacitance of the teflon capacitors, however, was less stable and experienced dramatic changes upon aging. For example, by the 5th week of aging, the teflon capacitor experienced a capacitance loss of about $46 \%$ when tested at $20 \mathrm{kHz}$. At week 15 , the reduction in the capacitance amounted to about $99 \%$ which is clearly indicative of failure of the capacitor due to loss in its capacitance. It is important to note that this loss in capacitance with aging increased with increasing frequency. Due to this capacitance loss no further testing of the teflon capacitors was performed after the 15 weeks.

The dissipation factor of the ceramic capacitors varied between 0.0001 and 0.004 for frequencies of $50 \mathrm{~Hz}$ and displayed better consistency at $20 \mathrm{kHz}$ over the entire aging period of 35 weeks, as shown in Figures 3 and 4. At $50 \mathrm{~Hz}$ and $20 \mathrm{kHz}$ the teflon capacitors showed little stability in loss factor and again the problems experienced after several weeks are very apparent. It should be noted that the dramatic changes in the electrical properties of the teflon capacitors are believed to be due to mechanical failures rather than the 
polymer film. Figure 5 depicts the leakage current as a function of aging time. The leakage current of the ceramic capacitors was relatively stable and appeared to not have been affected by the aging process. Figure 5 also clearly shows the rapid increase in leakage current that was experienced by the teflon capacitors during the early stages of the aging test.

Based upon these results and those of previous experiments, the combined effects of short-term thermal aging and applied electrical stressing have had minimal effects on the electrical properties of the ceramic capacitors while the effects on the teflon capacitors have been significant. This erratic behavior of the teflon capacitor when aged under combined electrical and thermal stressing is not clearly understood especially at the high frequencies. It is important to know that when these teflon capacitors were subjected only to thermal aging such a trend was not observed [6]. Further investigation is therefore necessary to fully understand what failure modes occurred and their associated mechanisms as well.

Although the electrical properties of the ceramic capacitors were not affected by these combined effects they did cause substantial physical changes in the lead structures of the capacitors. These structural changes may bave been caused by the $\mathrm{Sn}_{2} \mathrm{Ag}$, type solder used to make the electrical connections. The incompatibility of this solder with that used to attach the lead frames resulted in a possible re-alloying which led to the deterioration of the leads. This deterioration made it difficult to maintain the electrical connections throughout the testing period. There were no significant changes, however, in the electrical properties of the capacitors as a result. The manufacturer of the capacitors recommended that $\mathrm{Sn}_{10} \mathrm{~Pb}_{\mathrm{ma}} \mathrm{Ag}_{2}\left(268 \mathrm{C}\right.$ ) or $\mathrm{Sn}_{3} \mathrm{~Pb}_{n, 9} \mathrm{Ag}_{1.5}$ (309 C) type solders be used in the future.

\section{CONCLUSION}

The results of this experimental investigation indicated that the combined effects of short-term thermal aging along with applied electrical bias have caused failure of the metallized teflon film capacitors used in this study but had little influence on the electrical properties of the ceramic capacitors. Future experiments need to be conducted in order to investigate and determine the causes of the teflon capacitor failures. Other studies may include short and long term aging tests at full rated power, breakdown voltage tests at various temperatures, and the effects of nuclear radiation. These recommended studies would provide additional insight and knowledge about the stability of these types of power capacitors for high temperature space and terrestrial applications.

\section{ACKNOWLEDGMENTS}

This work was supported by NASA Lewis Research Center, Contract \# NAS3-27186, Task Order \# 5430-04, "High Temperature Power Electronics."

\section{REFERENCES}

[1]
A. N. Hammoud, E. D. Baumann, E. Overton, I. T. Myers, J. L. Suthar, W. Khachen, and J. R. Laghari, "High Temperature Dielectric Properties of Apical, Kapton, PEEK, Teflon AF, and Upilex Polymers", 1992 IEEE Conference on Electrical Insulation and Dielectric Phenomena, Victoria, British Columbia, Canada, October 18-21, 1992.

E. Sugimoto, "Applications of Polyimide Films to the Electrical and Electronic Industries of Japan", IEEE Electrical Insulation Magazine, Vol. 5, No. 1, 1989.

A. N. Hammoud, E. D. Baumann, I. T. Myers, and E. Overton, "Electrical Properties of Teflon and Ceramic Capacitors at High Temperatures", 1992 Intemational Symposium on Electrical Insulation, Baltimore, Maryland, June 7-9, 1992.

Component Research Company, High Reliability Film Capacitors, Catalog W.

Olean Advanced Products, Chip Capacitors No. AOL-0959-01.

E. Overton, A. N. Hammoud, E. D. Baumann, and I. T. Myers, "Thermal Aging Effects on the Electrical Properties of Film and Ceramic Capacitors", 1993 Electrical/ElectronicsInsulation Conference, Chicago, Illinois, October 4-7, 1993. 
Table 1.-Capacitors Specifications $[4,5]$

\begin{tabular}{|c|c|c|}
\hline Property & Tefion & Ceramic \\
\hline Capacitance $(\mu \mathrm{F})$ & 1.0 & 1.0 \\
\hline Capacitance Tolerance (\$) & 5 & \pm 10 \\
\hline Voluge (VDC) & 200 & 500 \\
\hline Operating Temperature (C) & -65 to +200 & -55 to +200 \\
\hline Dissipation Factor (\$) & $0.05 \mathrm{Max}(25)^{\circ} \mathrm{C}$ & $0.15 \mathrm{Max}(9) \mathrm{C}$ \\
\hline
\end{tabular}

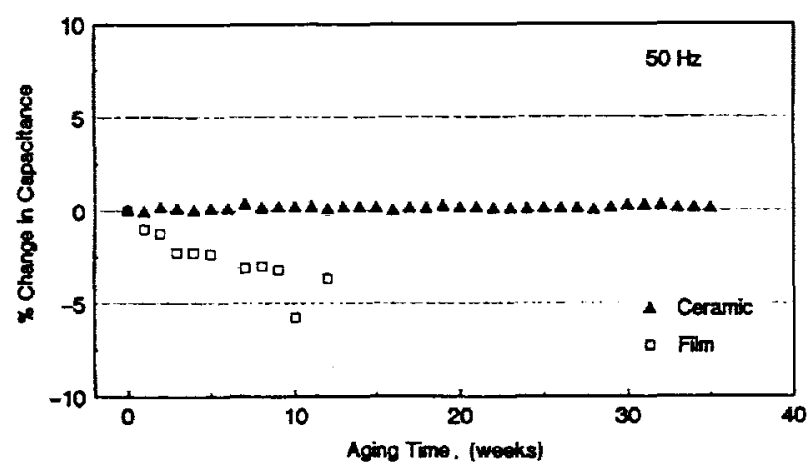

Figure 1.-Change in capacitance with aging time at $50 \mathrm{~Hz}$.

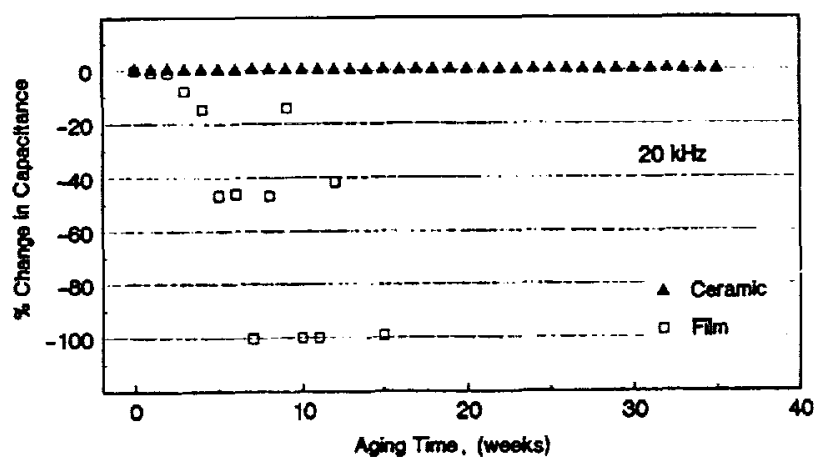

Figure 2.-Change in capacitance with aging time at $20 \mathrm{kHz}$.

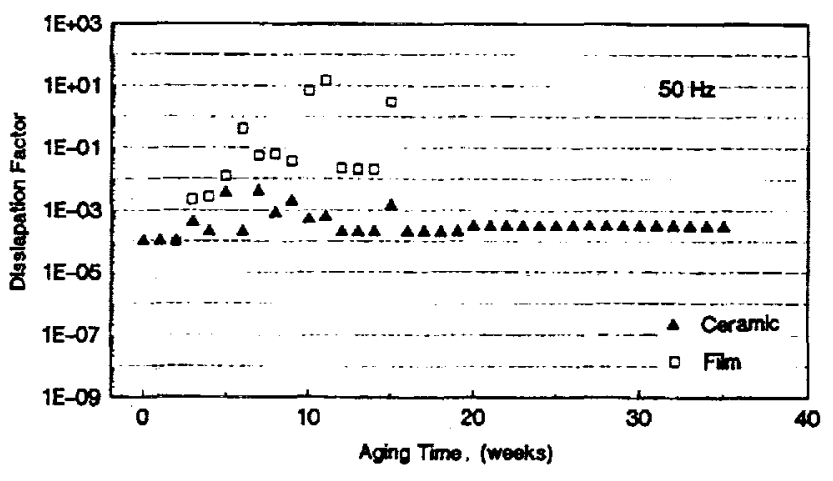

Figure 3.-Change in dissipation factor with aging time at $50 \mathrm{~Hz}$.

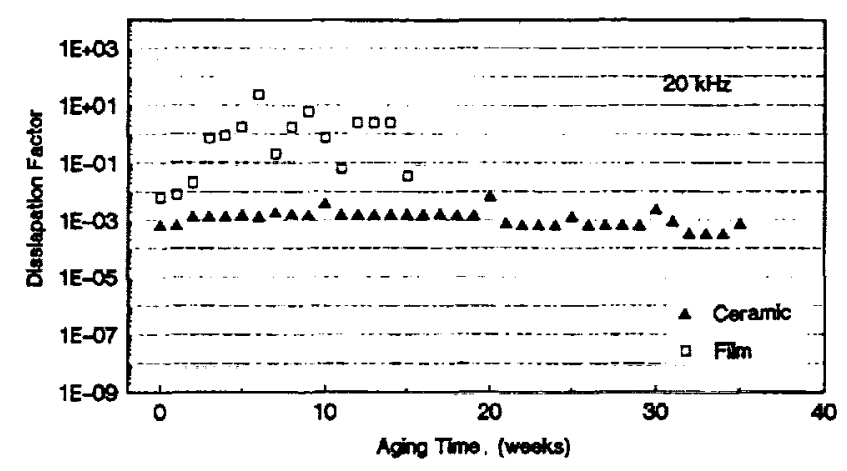

Figure 4.-Change in dissipation factor with aging time at $20 \mathrm{kHz}$.

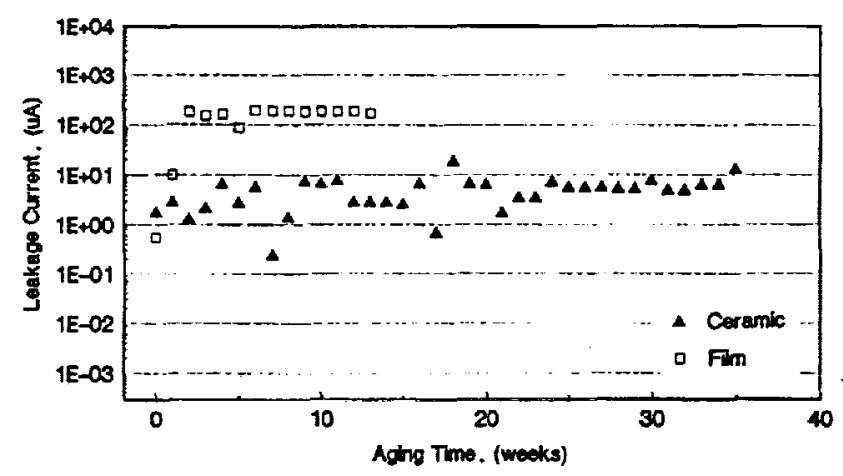

Figure 5.-Change in leakage current with aging time. 
Public reporting burden for this collection of information is estimated to average t hour per response, including the time tor reviewing instructions, searching existing data sources, in. Send comments regarding this burden estenato or any other aspect of this Davis Highway, Suite 1204. Arlington, VA 22202-4302, and to the Office of Management and Budget, Paperwork Reduction Project (0704-0188), Washington, DC 20503.

\begin{tabular}{|l|c|c|}
\hline 1. AGENCY USE ONLY (Leave blank) & $\begin{array}{c}\text { 2. REPORT DATE } \\
\text { May } 1994\end{array}$ & $\begin{array}{r}\text { 3. REPORT TYPE AND DATES COVERED } \\
\text { Technical Memorandum }\end{array}$ \\
\hline
\end{tabular}

4. TITLE AND SUBTITLE

May 1994

5. FUNDING NUMBERS

Effects of Combined Stressing on the Electrical Properties of

Film and Ceramic Capacitors

6. AUTHOR(S)

Eric Overton, Ahmad N. Hammoud, Eric D. Baumann, and Ira T. Myers

WU-506-41-41

7. PERFORMING ORGANIZATION NAME(S) AND ADDRESS(ES)

8. PERFORMING ORGANIZATION REPORT NUMBER

National Aeronautics and Space Administration

Lewis Research Center

Cleveland, Ohio 44135-3191

E-8881

9. SPONSORINGMONITORING AGENCY NAME(S) AND ADDRESS(ES)

10. SPONSORING/MONITORING AGENCY REPORT NUMBER

National Aeronautics and Space Administration

Washington, D.C. $20546-0001$

NASA TM-106605

11. SUPPLEMENTARY NOTES

Prepared for the International Symposium on Electrical Insulation sponsored by the Institute of Electrical and Electronics Engineers, Dielectrics and Electrical Insulation Society, Pittsburgh, Pennsylvania, June 5-8, 1994. Eric Overton, Eric D. Baumann, and Ira T. Myers, NASA Lewis Research Center and Ahmad N. Hammoud, NYMA, Inc., Engineering Services Division, 2001 Aerospace Parkway, Brook Park, Ohio 44142 (work funded by NASA Contract NAS3-27186). Responsible person, Eric Overton, organization code 5430, (216) 433-8189.

12a. DISTRIBUTIONAVAILABILITY STATEMENT 12b. DISTRIBUTION CODE

Unclassified - Unlimited

Subject Category 33

13. ABSTRACT (Maximum 200 words)

Advanced power systems which generate, control and distribute electrical power to many large loads are a requirement for future space exploration missions. The development of high temperature insulating materials and power components constitute a key element in systems which are lightweight, efficient, and are capable of surviving the hostile space environment. In previous work, experiments were carried out to evaluate film and ceramic capacitors for potential use in high temperature applications. The effects of thermal stressing, in air and without electrical bias, on the electrical properties of the capacitors as a function of thermal aging up to 12 weeks were determined. In this work, the combined effects of thermal aging and electrical stresses on the properties of teflon film and ceramic power capacitors were examined. The ceramic capacitors were thermally aged for 35 weeks and the teflon capacitors for 15 weeks at $200^{\circ} \mathrm{C}$ under full electrical bias and were characterized, on a weekly basis, in terms of their capacitance stability and electrical loss in the frequency range of $50 \mathrm{~Hz}$ to $100 \mathrm{kHz}$. DC leakage current measurements were also obtained. The results obtained represent the influence that short-term thermal aging and electrical bias, have on the electrical properties of the power capacitors characterized.

14. SUBJECT TERMS

Capacitors; High temperature; Power components

15. NUMBER OF PAGES

\begin{tabular}{|c|c|c|}
\hline $\begin{array}{c}\text { 17. SECURITY CLASSIFICATION } \\
\text { OF REPORT } \\
\text { Unclassified }\end{array}$ & $\begin{array}{c}\text { 18. SECURITY CLASSIFICATION } \\
\text { OF THIS PAGE } \\
\text { Unclassified }\end{array}$ & $\begin{array}{c}\text { 19. SECURITY CLASSIFICATION } \\
\text { OF ABSTRACT } \\
\text { Unclassified }\end{array}$ \\
\hline
\end{tabular}

